$\begin{array}{cl}\begin{array}{cl}\text { Revue } \\ \text { de /histoire } \\ \text { des religions }\end{array} & \text { Revue de l'histoire des religions } \\ & 2 \text { Religion, secret et autorité }\end{array}$

\title{
Une foi au secret ? Captivité, hommage à Dieu et clandestinité protestante (1685-1791)
}

Faith in Secret? Captivity, Homage to God and Protestant Clandestineness

(1685-1791)

\section{Chrystel Bernat}

\author{
(2) OpenEdition \\ Journals \\ Édition électronique \\ URL : http://journals.openedition.org/rhr/7771 \\ DOI : $10.4000 /$ rhr.7771 \\ ISSN : 2105-2573 \\ Éditeur \\ Armand Colin \\ Édition imprimée \\ Date de publication : 1 juin 2011 \\ Pagination : 175-205 \\ ISBN : 978-2200-92720-2 \\ ISSN : 0035-1423

\section{Référence électronique} \\ Chrystel Bernat, « Une foi au secret ? Captivité, hommage à Dieu et clandestinité protestante \\ (1685-1791) », Revue de l'histoire des religions [En ligne], 2 | 2011, mis en ligne le 01 juin 2015, consulté \\ le 01 mai 2019. URL : http://journals.openedition.org/rhr/7771 ; DOI : 10.4000/rhr.7771
}

Tous droits réservés 


\section{Une foi au secret? Captivité, hommage à Dieu et clandestinité protestante (1685-1791)}

Cette enquête explore, tout au long de la période de clandestinité du protestantisme français, les arcanes de la résistance spirituelle d'une communauté confessionnelle aux prises avec l'absolutisme et l'exigence d'unité religieuse du royaume. L'analyse porte sur les recours et les pratiques de dissimulation utilisés par les calvinistes pour déjouer l'imposition du dogme catholique. De cette foi contrainte au secret dont le Désert, né de l'oppression, dit en écho à la métaphore biblique l'épreuve et l'insoumission, l'on approchera le rôle vivifiant et celui, complexe, du secret à la lueur de pratiques cachées et de langages codés se heurtant à l'impératif chrétien de confesser publiquement sa croyance.

\section{Faith in Secret? Captivity, Homage to God and Protestant Clandestineness (1685-1791)}

This inquiry examines, over a long period of clandestineness for French Protestantism, the mysteries of the spiritual resistance of a religious community battling with the absolutism of the kingdom and its demand for religious unity. The analysis deals with the appeals and the concealed practices used by Calvinists to confound the Catholic dogma imposed on them. The vivifying role of this faith that is forced to be silent - whose Desert, born out of oppression, echoes the biblical metaphor in regards to ordeal and insubordination - will be examined alongside the complex role of secrecy through hidden practices and coded languages coming up against the Christian requirement to confess one's faith publicly. 
Il n'y a rien de caché qui ne doive être découvert, ni de secret qui ne doive être connu.

Matthieu 10, 26

En publiant la vérité, nous nous recommandons à toute conscience d'homme devant Dieu. 2 Corinthiens 4,2

Je ferai cela en présence de tout Israël et à la face du soleil. 2 Samuel 12, 12

Point culminant symbolique de la politique d'asphyxie du protestantisme, amorcée dès 1656 par le régime louis-quatorzien, l'édit de Fontainebleau entérine, à l'automne 1685, la proscription des calvinistes en proclamant l'interdiction de l'exercice public de la Religion Prétendue Réformée. Seuil législatif de l'exclusivisme catholique, la Révocation de l'édit de Nantes ne constitue pas le point d'orgue de la législation antiprotestante - plusieurs lois oppressives draconiennes lui succèdent - mais confirme l'éviction des huguenots pour plus d'un siècle. Il s'agit d'effacer la mémoire de la « fausse religion » et toutes traces du pluralisme confessionnel. Dans les faits, la chronologie est plus subtile. Pour nombre de protestants, arrêts et ordonnances préalables, missions bottées et dragonnades encadrant les conversions forcées au catholicisme ont ouvert les voies de la dissimulation dès 1679. De même, l'adoption par l'Assemblée nationale constituante, le 26 août 1789, de l'article X de la Déclaration des Droits de l'Homme, accordant la liberté de conscience, ne met pas un terme définitif à la clandestinité. La liberté de culte n'est obtenue que le 3 septembre 1791. Plusieurs éclipses ont lieu jusqu'à la loi du 8 avril 1802 qui, par les Articles Organiques, scelle le statut juridique des Églises réformées $^{1}$. Cependant, les deux dates signalent la phase aiguë de ce

1. La liberté de culte prononcée en 1791, réaffirmée par la loi du 21 février 1795, pâtit de plusieurs périodes de tensions religieuses. Ces éclipses liberticides procèdent d'interdits ponctuels (Convention nationale défendant l'exercice de tout culte religieux; Terreur imposant la fermeture des maisons d'oraison) et de la réactivation cyclique des clivages confessionnels durant la période révolutionnaire (bagarres sanglantes de Montauban et de Nîmes; camps de Jalès en 1790; insurrection avortée des royalistes cévenols en 1791 ; mouvements contre-révolutionnaires des catholiques du Languedoc en 1791-1793; Terreur blanche du Midi en 17931794). 
régime d'exclusion ${ }^{2}$. De fait, 1685 met la religion calviniste à l'interdit et relègue sa communauté dans la clandestinité, 1791 marque sa réintégration - l'usage de la dissimulation apparaissant par la suite davantage intermittent.

Dès lors, le recours au secret en milieu protestant semble inhérent à l'histoire du calvinisme français du XVIII ${ }^{\mathrm{e}}$ siècle qui croise l'histoire d'une destitution et d'une répudiation. D'emblée, pourtant, plusieurs nuances s'imposent du fait de la multiplicité des modes de résistance qui, loin d'emprunter uniquement au double jeu, passent ponctuellement par la résistance ouverte au processus d'éradication du protestantisme ${ }^{3}$. L'usage même du secret n'est pas sans recouvrir une quête inlassable de reconnaissance publique ${ }^{4}$. Sa pratique demeure complexe. Sans compter qu'en ce long siècle, la clandestinité et, partant, l'usage du secret sont d'intensité très inégale tant ils épousent les inflexions chronologiques des phases d'accalmie et de recrudescence de l'oppression religieuse, tant ils varient selon les provinces en fonction du zèle des autorités civiles,

2. L'Édit de Versailles, dit de Tolérance, du 17 novembre 1787, introduisit une première brèche dans le régime de clandestinité en octroyant une existence légale aux protestants. Néanmoins, tout en garantissant les droits de l'état civil aux sujets du royaume ne professant pas la religion catholique, l'édit ne reconnaissait pas la liberté de conscience. En 1787, la royauté maintenait la législation d'obligation religieuse et l'exclusivité du culte public catholique. Sur le maintien jusqu'en 1789 , les fondements de cette politique royale systématique d'obligation religieuse, et la législation codifiant les contraintes catholiques, voir Michel Péronnet, " Obligation catholique et monarchie française durant la période moderne », in Les Rabaut, du Désert à la Révolution, Montpellier, Presses du Languedoc, 1988, p. 41-67.

3. Ainsi par le biais des plaintes adressées au roi, à l'occasion de la révolte pacifique du pasteur Claude Brousson (1683) et des mouvements protestants de résistance spirituelle autour des prédicants du Midi (entre 1683 et 1700) - singulièrement en 1683-1684 lors du soulèvement du Camp de l'Éternel en Dauphiné et Vivarais, en 1687-1689 à l'occasion de projets de rentrée à main armée des protestants exilés, et en 1690-1692 autour de l'activité de la troupe du prédicant François Vivens -, lors de la révolte des réformés de Sancerre (1685) et des mouvements réfractaires aux conversions (1681-1685), des remous intra-protestants autour des modalités de résistance à l'oppression élaborées par le pasteur Pierre Jurieu (1689), lors de la prise d'armes camisarde en Bas-Languedoc (1702-1710), des révoltes des protestants de Mougon (1719), de Breloux (1742) et de Moncoutant en Poitou (1747), des mouvements d'opposition en Dauphiné, Languedoc et Poitou consécutifs à l'intensification des contraintes religieuses et à la campagne de rebaptisation au catholicisme (1750-1752).

4. Voir notamment Hubert Bost, « De la secte à l'Église. La quête de légitimité dans le protestantisme méridional au XVIII ${ }^{\mathrm{e}}$ siècle ", Rives nord-méditerranéennes, 10 (2002), p. 53-68. 
des velléités du clergé et de la ferveur des fidèles - catholiques et protestants. Ce recours ne peut être tenu pour immuable, il évolue au gré des vicissitudes et s'adapte au fil des impératifs que se fixent les proscrits : impératifs de survie d'abord, puis de redressement, enfin de (ré)intégration. Si un bémol s'impose dans les trente dernières années de l'exclusion légale du protestantisme - du fait d'un relâchement sporadique de la contrainte et d'une indulgence plus ou moins tacite à l'égard de l'exercice réformé -, le protestantisme n'en demeure pas moins interdit et donc clandestin jusqu'à la Révolution ${ }^{5}$. Ce dont témoignent en 1771 l'arrestation tardive du pasteur François Charmusy (dernier ministre martyr, surpris en chaire et mort en détention) et, au printemps 1789, la condamnation du pasteur Pierre Mordant ${ }^{6}$. Un phénomène que souligne aussi, trois jours à peine avant la Déclaration des Droits de l'Homme, le discours de Rabaut Saint-Étienne qui, à l'occasion de la discussion de l'article X, rappelle que les lois répressives n'ont pas été abolies et que les huguenots sont encore réduits à célébrer leur culte «dans les déserts »". Le Désert, c'est là l'expression singulière qui, empruntant à la culture biblique, symbolise le long siècle de retranchement mais aussi de résistance active aux persécutions religieuses. Ultime référence, avant l'obtention de la liberté de culte, à un terme générique fondamental qui recouvre un ensemble de pratiques clandestines imposées par l'oppression des consciences nous y reviendrons.

5. André Encrevé, « Désert », in Pierre Gisel (dir.), Encyclopédie du Protestantisme, Paris, Genève, PUF, Labor et Fides, $2006^{2}$, p. 308.

6. Cas ambivalent mais significatif de libéralités toujours menacées à la veille de la Révolution : $c f$. Frank Puaux, "Le dernier procès pour cause de religion au XVIII ${ }^{\mathrm{e}}$ siècle. Le pasteur P. Mordant et le Parlement de Rouen », Bulletin de la Société de l'Histoire du Protestantisme Français [dorénavant BSHPF], 26 (1877), p. 220-238; Amélie Lecoq, Du Désert au temple: itinéraire du pasteur cauchois Pierre Mordant, de l'Ancien Régime à l'Empire, Mémoire de Master 2, EPHE, 2008, t. I, p. 55-59.

7. Hubert Bost, «Le Désert des huguenots : une poétique de l'épreuve », Revue des Sciences Humaines, 258 (2000), p. 204. Si, pour certains réformés, la tolérance se manifeste dès avant 1789 - tel que le proclame, en 1788, le discours de Rabaut-Pomier: " autrefois nous étions forcés de dissimuler notre foi [...] aujourd'hui nous pouvons la manifester sans crainte »-, l'affirmation se situe à mi-chemin entre l'expérience vécue (et déjà la construction d'une mémoire de la clandestinité) et la volonté politique d'encourager l'autorité royale à accéder plus avant aux requêtes séculaires des protestants. Je remercie Céline Borello de m'avoir signalé ce document, publié dans le $B S H P F, 36$ (1887), p. 596-604 [extrait cité, p. 599]. 
Cependant, la clandestinité équivaut-elle à une pratique du secret? Si elle ne contredit pas la résistance déclarée - nous l'avons évoqué -, sa racine latine dit bien ce qui s'effectue " en secret", avec cette singularité d'y adjoindre la dimension d'illicite. C'est cette articulation de la dissimulation et de l'illégal, du défendu, de l'interdit qui nous importe au premier chef. Plus encore, le paradoxe d'un usage du secret placé au service d'une valorisation de la différence confessionnelle et d'une aspiration à une vie croyante licite.

L'historiographie du protestantisme moderne s'est peu intéressée à cet angle d'approche, à ce prisme spécifique du secret, qui est lui-même un mode de dissimulation ${ }^{8}$. Si le statut de clandestinité demeure l'objet de nombreux travaux et jalonne la thématique des Églises sous la Croix, l'analyse révèle l'absence d'une étude systématique des pratiques cachées, soumises à discrétion, relevant de la dissimulation ou de la simulation. Ainsi, une foule d'exemples émaille les recherches sans pourtant avoir suscité de synthèse à l'exception de l'une des pratiques les plus emblématiques de la résistance protestante que constituent les réunions de prières et les assemblées religieuses interdites ${ }^{9}$. Pourtant, l'éventail de ce recours au secret et des stratégies transgressives dictées par la répression est des plus larges. Il se déploie bien au-delà des rassemblements nocturnes en une déclinaison d'attitudes et de pratiques cultuelles et discursives qu'il reste à approcher. Chacune d'elles filtre d'un corpus dépassant la source judiciaire et pénale venue éventer le secret et déjouer la pratique clandestine : correspondances privées, mémoires des proposants et des pasteurs du Désert, actes et copies des arrêts des synodes provinciaux et nationaux, registres paroissiaux, lettres pastorales du royaume et du Refuge, avis, instructions pour les exercices de piété, apologies, libelles, requêtes donnent prise à ces pratiques dissimulées

8. Claude Giraud, Du secret. Contribution à une sociologie de l'autorité et de l'engagement, Paris, L'Harmattan, 2005, p. 50.

9. Thème privilégié auquel s'ajoute celui de la littérature clandestine - plusieurs travaux collectifs, consacrés aux processus d'élaboration, diffusion et circulation des idées et des opuscules protestants interdits, ont été publiés dans La lettre clandestine: Olivier Bloch, Censure et clandestinité aux XVII et XVIII ${ }^{e}$ siècles; Geneviève Artigas-Menant, Antony McKenna (dir.), Anonymat et clandestinité aux XVII et XVIII ${ }^{e}$ siècles, Paris, PUPS, 2000 ; Id., Protestants, protestantisme et pensée clandestine, Paris, PUPS, 2005. 
répondant d'un temps d'exclusion. Contrairement à ce que l'on pourrait croire, le sens profond de l'usage du secret en milieu protestant réside aussi dans une partie de ces témoignages délibérément publics.

Si le secret apparaît comme un rouage essentiel des modalités de maintien et d'existence du protestantisme, une distorsion s'impose d'emblée entre recours au secret et nécessaire visibilité, entre dissimulation et revendication. Ce paradoxe, symptomatique d'une double particularité du phénomène, invite à interroger les seuils informels et les frontières mouvantes du secret. Plus encore, il questionne la dichotomie sous-jacente entre vulnérabilité (qu'impose la discrétion) et manifestation de force, entre pratique par essence occulte et performativité démonstrative face à l'autorité. Dès lors, faut-il considérer que le secret ne recèle que doléances tacites et attentes implicites ? En quoi son usage et les réclamations qu'il charrie sont autant d'exigences affichées et de requêtes explicites? Il s'agit d'observer quelles pratiques clandestines sont utilisées pour contourner l'interdit religieux, et comment l'usage de la dissimulation s'articule à l'impératif chrétien de confesser publiquement sa croyance. Y aurait-il un bon et un mauvais usage du secret? Quelles polémiques soulève-t-il, au sein de quels litiges se loget-il? Du reste, le terme de foi au secret est-il adéquat? Pour tenter de répondre, revenons à la notion centrale et polysémique de Désert à laquelle est arrimé un ensemble de pratiques dissimulées.

\section{LE DÉSERT HUGUENOT : POLYSÉMIE D’uNE PIÉTÉ AU SECRET}

Le terme, utilisé dès 1616 à l'occasion de la parution anonyme des Tragiques d'Agrippa d'Aubigné et qui s'est imposé au tournant des années 1680 avec Claude Brousson, renferme à la fois une réalité pratique, une symbolique et une notion historique ${ }^{10}$.

10. Marianne Carbonnier-Burkard, «Le Désert des protestants français », Les Cahiers protestants, 5 (1999), p. 27-33. Il ne s'agit pas de prétendre à une nouvelle étude du Désert, notion déjà abondamment travaillée, mais d'analyser, à partir des spécificités dégagées par l'historiographie, son articulation avec la pratique du secret. 


\section{Temps et espaces, contraintes et épreuves d'une croyance proscrite}

Le Désert désigne d'abord une réalité oppressive et une situation de clandestinité imposée à la fois par une interdiction et une obligation religieuses (proscription du culte calviniste et imposition du dogme catholique). Le Désert désigne encore une période séculaire de persécutions ${ }^{11}$ et un espace de retrait autant qu'un théâtre spirituel - théâtre sauvage établi dans les lieux retirés et solitaires, dressé dans les garrigues, les clairières et les sous-bois, dans les carrières, les cavernes ou l'antre des rochers. Si le Désert s'ancre principalement en terre ferme, d'abord dans les provinces méridionales (Cévennes, Vivarais, Dauphiné, Haut et Bas-Languedoc) avant de gagner divers terroirs de la dorsale huguenote, d'autres Déserts, plus éphémères, s'improviseront dans les ports et sur les mers, au mouillage ou au large des côtes. Là sont les décors variables où se jouent, à l'abri de la soldatesque, des espions et des délateurs, l'expression et la manifestation communautaire d'une croyance proscrite par le pouvoir après le rasement des temples et l'exil forcé des pasteurs. Le Désert est ainsi le lieu de prédilection où se noue par et dans le secret la survie d'une piété bafouée au nom de l'unité religieuse du royaume. Lieu d'épreuve sans cesse menacé et exposé à la répression, il est le refuge de la foi poussée hors du sanctuaire où prédicants et pasteurs se cachent pour échapper aux traques du pouvoir et maintenir la Parole. Comparé à l'« Arche» durant le Déluge, il est l'asile où les fidèles, appelés à se réunir, se retrouvent en assemblées clandestines pour prier Dieu et chanter ses louanges ${ }^{12}$. Ceci dit en substance que le secret n'équivaut pas, ici du moins, au silence. En ce Désert huguenot résonnent la lecture de la Bible, les prédications et les chants des psaumes.

11. L'on distingue généralement deux phases : le «Désert héroïque » relevant d'un temps de violences antiprotestantes intensives entre 1685 et 1760 , et un « second Désert » bénéficiant du lent processus d'apprentissage de la tolérance et de moindres tribulations entre 1760 et 1787.

12. Assignation et représentation qui jalonnent toute la période du Désert : Antoine Court, Sermon dans lequel on fait voir la nécessité de l'exercice public de la Religion. Sur ces paroles de l'apôtre saint Paul aux Hébreux, chap. X, v. 25 : "ne quittons point nos mutuelles assemblées, comme quelques-uns ont de coutume ». Prononcé par Antoine Court au Désert, chez D. L., 1718, p. 35; Bibliothèque du protestantisme français $[\mathrm{BPF}], \mathrm{ms} 717^{2}$, pièce 38 : sermon de Rabaut Saint-Étienne prononcé le 22 février 1776. 
Instructions, consolations et hommages à Dieu y font écho ${ }^{13}$. De même, les assemblées clandestines, quoiqu'élaborées en secret - réunies sur «l'avis de quelques personnes préposées à ce sujet dans chaque paroisse ", écrit Antoine Court -, ont vocation au témoignage public interne, par l'exercice commun et une reconnaissance mutuelle de la dépendance à Dieu ${ }^{14}$. Ici, l'usage du secret sert paradoxalement une révélation. En retrait se déclarent les marques publiques intra-confessionnelles d'une adoration.

\section{Affiliations bibliques : l'assimilation aux épreuves du peuple hébreu}

Le Désert est aussi une symbolique et une attitude. Il est ce qu'Hubert Bost a appelé une poétique : poétique en référence au peuple hébreu qui, après sa sortie d'Égypte, erra quarante ans dans le désert avant d'entrer en Terre promise. Plus qu'une filiation, l'emprunt crée une véritable analogie avec le peuple d'Israël dont les protestants pensent revivre, en un face-à-face avec Dieu, l'épreuve imposée durant son exode. Il est en ce sens un support de symboles symbole de la contrainte et du châtiment d'une infidélité mais aussi de la révélation, de la providence, de la consolation, de l'élection divine - et jusqu'à une attitude qui emprunte, dans l'itinérance et la clandestinité, à l'image christique ${ }^{15}$. Le Désert n'est pas seulement la manifestation de l'Église ramenée à sa quintessence, il est encore l'incarnation tangible du peuple assemblé, et l'expérience quotidienne d'une foi que les décors arides rapprochent des tribulations de l'Église primitive ${ }^{16}$. Car c'est au secret que se dit la

13. Paul de Félice, Sermons protestants prêchés en France de 1685 à 1795, Paris, Fischbacher, 1885.

14. [Antoine Court], Apologie des Protestans du Royaume de France sur leurs assemblées religieuses, Au Désert, 1745, p. 5, 10, 14, 16.

15. Si l'affiliation est multiple, le retrait de Jésus sur le mont des Oliviers pour éviter de s'exposer aux poursuites du Sanhédrin et à l'accusation de sédition n'est pas sans analogie avec le Désert des réformés : il ne s'agit pas de se soustraire à l'épreuve mais de préserver l'établissement du règne de Dieu. À l'instar du Christ, les protestants useront de prudence pour ne pas compromettre son œuvre. Comme lui, ils pensent agencer, en un contexte de menace et depuis des lieux écartés, l'avancement de son règne. Sur l'usage du secret dans la Bible, voir Charles Dardier, Pourquoi Jésus-Christ exigea-t-il souvent le secret, au sujet de ses miracles et de son titre de Messie?, Strasbourg, Impr. Schuler, 1843.

16. Sur cette symbolique, dont je reprends ici les principaux traits, voir l'étude fouillée de H. Bost, «Le Désert des huguenots : une poétique de l'épreuve », 
vraie Église et que se noue l'Alliance avec Dieu ${ }^{17}$, c'est au Désert - lui-même espace de secret ${ }^{18}$ - que Dieu rassasie son peuple ${ }^{19}$. Le dehors devient le dedans et l'espace d'exclusion le théâtre de la Promesse, celle d'une délivrance à venir. Si secret il y a à se réunir en assemblées et à gagner le Désert, il ne vise pas à cacher mais plutôt à préserver - un peuple, une fidélité, une espérance, fût-ce en des « lieux souterrains ${ }^{20} »$.

\section{Foi en clandestinité, mouvement de résistance et de redressement du peuple réformé}

Cependant, si le Désert revêt une symbolique (figurant les contours d'un maquis spirituel) et une esthétique (dressant « un temple naturel aux dimensions du Créateur $\left.{ }^{21} »\right)$, l'entrée au Désert relève d'un acte de résistance : acte de résistance à la répression et à l'abjuration pour prévenir la chute ${ }^{22}$ - parfois de repentance et de réparation après l'apostasie -, le Désert signale un parti pris d'opposition au processus de catholicisation forcée. En ce sens, il est un acte de rupture face aux lois jugées iniques, une «dissidence clandestine protestante à l'intérieur du royaume ${ }^{23} \gg$. Le secret sert ici une protes-

art. cité. Sur l'identification avec l'Israël biblique, $c f$. également Paul Viallaneix, « Peuple du Désert », BSHPF, 140 (1999), p. 297-303.

17. Solange Deyon cite ces vers éclairants d'Agrippa d'Aubigné extraits de la Préface des Tragiques : «Si on te demande pourquoi/Ton front ne se vante de moi,/Dis-leur que tu es un posthume/Desguisé, craintif et discret,/Que la vérité a coutume/D'accoucher en un lieu secret » : Solange Deyon, « La résistance protestante et la symbolique du Désert », Revue d'histoire moderne et contemporaine, 18 (1971), p. 241.

18. Jean Delorme, Au risque de la Parole, Paris, Seuil, 1991, p. 22.

19. Claude Brousson, La Manne mystique du Désert, ou sermons prononcés en France dans les déserts et dans les cavernes durant les ténèbres de la nuit de l'affliction, les années 1689, 1690, 1691, 1692 et 1693, 3 vol., Amsterdam, H. Desbordes, 1695.

20. A. Court, Sermon, op. cit., p. 35.

21. M. Carbonnier-Burkard, «Le Désert des protestants français », art. cité, p. 32 .

22. Contre la tentation d'abandonner Dieu, il est recommandé de rejoindre l'« azile » des bois et les fentes des rochers à l'instar des anciens fidèles dont parle l'Écriture : Pierre Encontre, Lettre de plusieurs reformés de France qui ont abandonné la cause de l'evangile. À ceux qui ont succombé sous la persecution, éd. par Abric Encontre, Trois lettres du Refuge écrites de l'exil aux églises sous la croix (1685), Paris, Grassart, 1877, p. 25.

23. M. Carbonnier-Burkard, «Le Désert des protestants français », art. cité, p. 27. 
tation, une réclamation. Cadre de riposte à la contrainte religieuse où se ménagent les témoignages de loyauté envers le monarque ${ }^{24}$, le Désert n'en demeure pas moins l'affirmation de la primauté de Dieu et d'une croyance sur la volonté du prince ${ }^{25}$. Il est le théâtre d'un refus de la domination des consciences, une tentative fervente de les extirper des $"$ fers $^{26}{ }^{2} »$. Lieu théologique et cadre d'un appel au redressement spirituel - initié autant par les fidèles que valorisé par le corps pastoral -, le Désert sert encore d'écrin à un programme de restructuration ecclésiologique, disciplinaire, doctrinale. Protestants et prédicants, bientôt aidés de pasteurs du Désert formés à partir de 1720 au séminaire clandestin de Lausanne, relèvent une à une leurs institutions : consistoires, colloques, synodes via un mouvement de restauration amorcé, le 21 août 1715 , dans une « carrière abandonné $e^{27} \gg$. Au fil des décennies, le Désert devient le lieu de réaffirmation - voire de refondation et de réactualisation - de l'orthodoxie calvinienne bousculée, après l'exil massif des pasteurs au Refuge, par les tendances millénaristes (mouvements prophétiques, 1680-1715/1730), les tentations radicales (prise d'arme camisarde, 1702-1705/1710) et une appropriation populaire de la Parole. Étendard d'une fidélité à la foi réformée, le Désert est cette intrication d'aspirations libertaires et d'engagements imposés par la clandestinité. Il est l'espace de survivance que se taillent les réformés dans un pays d'interdits, une trouée dans le tissu législatif oppressif. À revers d'une inexistence juridique, il désigne le lieu d'une ténacité

24. Témoignages d'allégeance renforcés après le soulèvement camisard: Antoine Court, Mémoires pour servir à l'histoire et à la vie d'Antoine Court (1695-1729), éd. Pauline Duley-Haour, Paris, 1995, p. 98, 106-108; BPF, Papiers Court, $\mathrm{ms} \mathrm{n}^{\circ} 617$ Q, p. 479-480.

25. Claude Brousson, Lettres et opuscules de feu Mr. Brousson, Utrecht, Guillaume vande Water, 1701, p. 35, 192; A. Court, Mémoires, op. cit., p. 74-75, 105, 107; Abrégé d'histoire apologétique ou Défense des réformés de France, qui sert de réponse à l'Instruction pastorale sur la persévérance en la foi et fidélité pour le souverain, de M. de Basnage datée du 19 avril 1719, éd. in A. Court, Mémoires, op. cit., p. 129, 134-137.

26. Pierre Jurieu, Lettres pastorales adressées aux fidèles de France qui gémissent sous la captivité de Babylon. Présentation par Robin Howells, Hildesheim, Olms, 1988, lettre XIV (15 mars 1688), p. 108-109.

27. Les synodes du Désert. Actes et règlements des synodes nationaux et provinciaux tenus au Désert de France de l'an 1715 à l'an 1793, éd. par Edmond Hugues, Paris, Fischbacher, 1885, t. I, p. XXI, LV. Voir aussi Yves Krumenacker, «L'élaboration d'un "modèle protestant" : les synodes du Désert », Revue d'histoire moderne et contemporaine, 42 (1995), p. 46-70. 
confessionnelle - et d'une (re)naissance communautaire - conditionnée par le secret. Pourtant, l'association du Désert et de l'histoire de la restauration du protestantisme à celle « obscure d'une société secrète » établie par Edmond Hugues est-elle fondée ${ }^{28}$ ?

\section{LA CLANDESTINITÉ AU QUOTIDIEN : USAGES DU SECRET}

En ces temps d'interdit, tout n'est pas secret, tout ne se fait pas en secret. La résistance et le vécu de la foi relèvent parfois seulement de la discrétion, de la prudence, de la dissimulation, du double jeu qui consiste à donner des signes extérieurs de catholicité tout en préservant sa croyance ${ }^{29}$. Néanmoins, en précipitant toute une communauté dans la clandestinité, la persécution ouverte qu'entérine la Révocation - renforcée par la Déclaration du 13 décembre 1698 qui valorise l'application rigoureuse des prescriptions, puis par celle du 14 mai 1724 tenue par le clergé pour "monument précieux » de l'attachement du roi au catholicisme ${ }^{30}-$, impose aux réformés de recourir quotidiennement à des pratiques dérobées, cachées à l'autorité, pour à la fois se soustraire aux obligations religieuses catholiques (enseignement, messe, sacrements) et préserver l'exercice du culte protestant.

\section{Enjeux de la confidentialité face à l'interdit}

La confidentialité relève bien souvent de l'impératif. Un secret éventé ou mal préservé mène, selon la gravité de la transgression, de l'amende à la potence : une assemblée illicite découverte conduit les femmes en prison, les hommes aux galères, le prédicant ou le pasteur à l'échafaud, ses biens confisqués, sa maison rasée, et les villages alentour au pillage ou au logement de la soldatesque. En ce long siècle, la mort menace auteurs et assistants des réunions de prières secrètes et les candidats à l'exil ${ }^{31}$. Amende honorable

28. Les synodes du Désert, op. cit., t. I, p. XLII.

29. Élisabeth Labrousse, «Diversité des formes de la résistance huguenote à l'abjuration », in Id., Conscience et conviction. Études sur le XVII siècle, ParisOxford, Universitas-Voltaire Foundation, 1996, p. 248-258.

30. M. Péronnet, «Obligation catholique et monarchie française », art. cité, p. 61.

31. Bibliothèque de Genève [BGE], Ms Court $\mathrm{n}^{\circ} 17 \mathrm{~B}:$ Relation des principaux faits qui sont arrives dans cette province du Dauphiné au sujet de la Reli- 
ou amende pécuniaire exorbitante (individuelle ou collective), bannissement temporel ou perpétuel (de la généralité ou du royaume), enfermement au couvent et dans les séminaires, mort civile, déportation, exécution sont autant de menaces qui pèsent sur les infractions clandestines $^{32}$, autant de sentences que l'usage du secret cherche à détourner. Malgré l'extrême variabilité des situations et donc des pratiques selon les périodes, malgré la prévalence des impératifs que se fixent les proscrits (du « secret » au moindre « éclat», de la circonspection au témoignage public) ${ }^{33}$, la prudence est de rigueur. Il faut pourtant insister sur ces fluctuations qui déterminent pour beaucoup la pratique du secret. Pratique relâchée lors des phases d'accalmie de la répression - nettement ressenties en temps de guerres extérieures qui détournent la menace -, et plus soutenue lors des phases de paix, propices à une réactivation de la législation oppressive ${ }^{34}$. Pratiques disparates aussi selon les provinces (souvent de la montagne au piémont, parfois d'une vallée, d'une place et d'un

gion Protestante depuis la cassassion de l'Édit de Nantes, fo169-170, 172; Jean Cavalier, Mémoires sur la guerre des Camisards, éd. Frank Puaux, Paris, Payot, 1987, p. 34, 39, 44 et n. 1, p. 44; A. Court, Mémoires, op. cit., p. 89-90, 117 ; Louis-Marie de Meschinet de Richemond, L'Église sous la Croix. Les protestants rochelais depuis la révocation de l'édit de Nantes jusqu'au Concordat, 1685-1802, Saintes, Impr. de Lassus, 1865, p. 9.

32. Élie Benoist, Histoire de l'Édit de Nantes, 5 vol., Delft, A. Beman, 16931695; C. Brousson, Lettres et opuscules, op. cit., lettres des 28 mars et 19 avril 1698, p. 317-318, 320; A. Court, Mémoires, op. cit., p. 31, 59, 65-66; BPF, ms 274 : Journal d'Étienne Durand, $\mathrm{f}^{\circ} 5$.

33. Cf. les actes du synode des Cévennes du 21 août 1715 (art. III); du synode national du Vivarais du 16 mai 1726 (art. V); du synode national du Languedoc du 18 au 18 août 1744 (art. X) : Les synodes du Désert, op. cit., t. I, p. 2, 55, 190 et p. XXXIII-XXXIV; [A. Court], Apologie, op. cit., p. 5, 30-32.

34. Ces oscillations correspondent à des phases d'inflexion répressive liées à des mesures moins rigoureuses (déclaration du $1^{\text {er }}$ février 1669) et à une application moins stricte de la législation antiprotestante (1672-1679, 1715-1723, 17301748), notamment du fait d'un relâchement de l'étau oppressif lors de la Régence (1715-1723), des préoccupations extérieures ponctuelles (préparatifs de guerre contre les Provinces-Unies en 1672 - répit très inégal lors de la guerre de la Ligue d'Augsbourg (1688-1697) et de la guerre de Succession d'Espagne (1702-1714), mais de nouveau manifeste à l'occasion de la guerre de Sept Ans en 1756), puis des manifestations récurrentes de tolérance de la différence religieuse (entre 1765 et 1787) malgré de fortes disparités selon les provinces et la ferveur des acteurs locaux. Sur le ressenti de cette alternance parmi les pasteurs et les fidèles, $c f$. notamment au terme de la guerre d'Augsbourg: C. Brousson, Lettres et opuscules, op. cit., p. 302, 313, 317; Id., Requestes envoyées au Roy de France par ses sujets protestans au sujet de la nouvelle persécution qu'on exerce contre eux depuis la paix générale, La Haye 1698; J. Cavalier, Mémoires, op. cit., p. 37, 41. 
quartier à l'autre encore dans les années 1760$)^{35}$, selon le bénéfice aléatoire des considérations sociales, l'attitude peu ou prou conciliante du bas clergé et des officiers royaux, la détermination des subdélégués d'intendants, la motivation des garnisons locales, l'audace des réformés et les armes de riposte dont chacun dispose. Autant de paramètres qui doivent être pris en compte dans une approche de l'usage protestant du secret qui ne relève pas d'une pratique uniforme et stable mais de comportements sans cesse adaptés à la plus ou moins grande rigueur des temps et des adversaires.

Cependant, même de polichinelle - face aux conversions feintes, aux «assemblées secrètes ${ }^{36}$ » réunies dans les campagnes et aux « mariages bénis à la lune ${ }^{37} »$, au « petit commerce de lettres ${ }^{38}$ », au redressement des écoles et à l'usage de locaux servant de lieux de culte -, le secret est encore observé tard dans le siècle. À quelles fins? Celles d'échapper à la sanction, de se préserver des officiers zélés, de ménager les velléités des catholiques les plus intransigeants et de garder la confiance des plus permissifs, de ne pas heurter de front l'autorité du souverain et de ne pas compromettre les libéralités progressivement acquises ${ }^{39}$. D'apparence futile, le secret de polichinelle a un double rôle : témoigner sans provoquer, tolérer sans avoir à cautionner. Avant cela, il demeure souvent incontournable, plein et entier. Son usage n'est pas qu'un moyen. Il devient

35. Extrême variabilité qu'illustre de manière exemplaire la correspondance de Simon Lombard (1739-1818) avec ses compagnons proposants du Languedoc : Charles Dardier, La vie des étudiants au Désert d'après la correspondance de l'un d'eux, Simon Lombard (1756-1763), Genève, Impr. Schira, 1893, cf. particulièrement p. 23, 31, 38-39, 46, 47-49, 55-57, 73-75. On retrouve des nuances semblables en 1767 à La Rochelle, en Saintonge et en Poitou : lettre du 22 décembre 1767 à un protestant d'Hambourg citée in L.-M. de Meschinet de Richemond, L'Église sous la Croix, op. cit., p. 20-21.

36. Tel que le relève Mgr Le Camus, évêque de Grenoble, in Les synodes $d u$ Désert, op. cit., t. I, p. VII-VIII.

37. Daniel Benoit, L'Église sous la croix, étude historique, Toulouse, Société des Livres religieux, 1882, p. 252.

38. C. Brousson, Lettres et opuscules, op. cit., p. 56.

39. Tendance qui filtre entre autres de la correspondance de Malesherbes avec l'intendant Reverseaux de La Rochelle en 1776 citée in L.-M. de Meschinet de Richemond, L'Église sous la Croix, op. cit., p. 22; de celle du pasteur François Gobinaud avec Paul Rabaut en 1785 citée in Théodore Maillard, Les Églises réformées poitevines sous la croix : l'enseignement de la jeunesse chez les réformés du $X V I^{e}$ au XVIII siècles, s.1. 1926, p. 20; de la lettre de Paul Rabaut à Lombard et aux anciens du consistoire d'Uzès, 3 avril 1778 citée in Ch. Dardier, La vie des étudiants au Désert, op. cit., p. 95-96. 
une modalité d'existence étroitement liée à la clandestinité. Si le Désert fait figure de structure secrète du protestantisme, l'usage du secret ne vaut pas uniquement pour les rassemblements pieux mais accompagne la vie de proscrits des fidèles et des prédicateurs. Pratique implicite ou objet de recommandation et de réglementation, il structure les modes de survie et de redressement : procédés de communication et processus de réorganisation (maintien de la Parole, enseignement et encadrement de la prédication, relèvement des églises, rétablissement de la discipline et restructuration des fonctions pastorale et synodale).

\section{Modes et pratiques du secret : les échappées à l'oppression}

Le secret apparaît au centre de la pastorale de substitution qui rapidement s'érige face à l'interdit. Il réside au cœur des pratiques cultuelles car c'est à l'écart que se maintiennent d'abord le catéchisme et la prière (entretenus à mots couverts au foyer, en famille ou entre voisins $)^{40}$; c'est à l'abri des regards que se déroule le culte assisté de sentinelles et se redéfinit une discipline élaborée dans des maisons d'emprunt. C'est encore en retrait - au Désert, dans les chapelles des ambassades des nations protestantes, sur les navires battant pavillon hollandais, dans les places étrangères situées aux abords des frontières du royaume - que se renouvellent rites et liturgie (célébration de la Cène, administration des baptêmes, bénédiction des mariages). Avant de s'adresser au pouvoir, c'est en petit groupe que se partage une piété illicite : prières au creux des ravins aussi bien que dans les clèdes, les granges et les corps de fermes isolés, au fond des cours, dans les arrière-boutiques et les remises, à fond de cale ou sur les pontons des bateaux éloignés du rivage. De même, c'est en secret que se dressent en Provence, Béarn, Guyenne, Saintonge, Normandie ou Picardie des embryons d'Églises dans des maisons particulières ${ }^{41}$. Au cœur des compor-

40. Par ailleurs, s'il est formellement interdit aux femmes de prêcher, le synode provincial du Vivarais du 26 juillet 1721 (art. XVIII) valorise leur instruction itinérante et discrète de la jeunesse «de maison en maison »: Les synodes $d u$ Désert, op. cit., t. I, p. 27.

41. Cf. notamment Fernand Bessière, Le Mariage des Protestants au Désert de France au XVIII ${ }^{e}$ siècle, Cahors, Impr. Coueslant, 1899, p. 10, 12-13; L.-M. de Meschinet de Richemond, L'Église sous la Croix, op. cit., p. 12-13, 16, 23; Les synodes du Désert, op. cit., t. I, p. XV, XLVII-XLVIII. 
tements, il réside dans le repli secret des consciences, dans les silences obtus et le refus de révéler les informations connues ${ }^{42}$, dans le crachat discret de l'hostie à l'église pour éviter la communion papiste ${ }^{43}$, dans les morts cachées pour éviter l'extrêmeonction catholique, dans les enterrements clandestins (au sein des domaines, dans les caves ou les jardins) pour soustraire les corps à la voirie, dans les récupérations nocturnes au gibet des cadavres pour leur assurer une sépulture. Billets de prières désormais fragmentés, feuillets de l'ancienne discipline ou de la Bible et bribes de sermons segmentés, copie des décisions des synodes minutieusement pliées, dissimulées dans les doublures des vestons ou sous la coiffe, petits livres interdits enveloppés dans les mouchoirs accompagnent cette geste de l'ombre ${ }^{44}$. Le secret jalonne aussi les pratiques textuelles : énoncés testamentaires codés et lapidaires pour contourner les exigences catholiques par l'usage de formulations choisies ou d'imprécisions volontaires pour éviter l'invocation des saints, de la Vierge et l'arsenal des références catholiques ${ }^{45}$. Il se lit encore à rebours de résistances plus ténues, en filigrane de procédés langagiers évitant toute allégeance à l'Église catholique : stratagèmes plus ou moins discrets prégnants dans les déclinaisons d'identité évasives mais limpides qui, face au pouvoir, tentent de déjouer l'appartenance au catholicisme (prédicants se disant « de la religion de Dieu », prophètes voulant être « de la meilleure religion $»)^{46}$. Terrés dans les maisons ou errants dans les bois pour éviter la messe $\mathrm{e}^{47}$, les réformés multiplient les caches à l'intention de « ceux qui pour la foi errent dans les déserts » : mise à disposition confidentielle de locaux pour servir aux exercices de piété, aux

42. BGE, Ms Court ${ }^{\circ} 17$ B : Memoires de Genouillac, $\mathrm{f}^{\circ} 43 / \mathrm{p} .23$ (menace contre les « muet[s] volontaire[s] »).

43. BPF, Papiers Court, ms 617 B : Mémoire de Gaubert, fo735-736. D'autres, se sacrifiant, communient plusieurs fois sous différents noms pour masquer leurs coreligionnaires : BPF, ms 274 : Journal d'Étienne Durand, fo5.

44. Mémoires de Bonbonnoux chef camisard et pasteur du Désert, éd. Jules Vielles, En Cévennes, 1883, p. 111.

45. Gabriel Audisio, «La résistance passive des huguenots au XVIII ${ }^{\mathrm{e}}$ siècle : le Désert », in $I d$. (dir.), Religion et exclusion, $X I I^{e}-X V I I I^{e} S$., Aix-en-Provence, PUP, 2001, p. 139.

46. Emmanuelle Carpuat, Le Vin du malheur et le feu de la langue. Les procès de prophétisme dans l'intendance de Montpellier 1685-1715, mémoire de maîtrise, Toulouse, 2003, p. 143-145.

47. BGE, Ms Court n 17 B : Mémoire de Jean-Paul Ebruy, f ${ }^{\circ} 122$. 
réunions des consistoires et des synodes, aménagement de retraites secrètes dans des caves ou des greniers à foin, dissimulées dans des tonneaux enfouis, dressées dans des monceaux de pierres ou des trous de murailles ${ }^{48}$. À l'abri des regards, ils assurent la sécurité et les déplacements clandestins des prêcheurs (fidèles délogeant les prédicants d'une maison pour les conduire dans d'autres gîtes en cas de danger; auditeurs anonymes les abordant pour les orienter le temps d'une course; hommes de confiance les guidant dans les bois ou les faubourgs) ${ }^{49}$. Les mémoires des prédicants Roche et Fauché, Martel et Lavérune, lui-même compagnon de Vivens, Brousson, Rouvière et Teissier, ceux de Court, Bonbonnoux ou Lombard évoquent ces itinérances secondées, ces concours secrets de « gens assurés » favorisant les liaisons épistolaires, avertissant de la proximité des détachements royaux, relayant auprès des fidèles l'heure et l'endroit du service religieux, se chargeant de la sécurité des assemblées ${ }^{50}$.

\section{Le secret pour règlement : recommandations et usages des prédicateurs}

La répression et la clandestinité obligent les réformés à repenser la façon et les moyens d'exprimer leur foi, de faire vivre leurs communautés, d'organiser leurs Églises. Pour échapper aux délations et aux poursuites, prédicants, proposants, pasteurs, instructeurs et régents recourent au secret et en agencent l'usage. En matière de foi, il sera invariablement considéré comme un pis-aller. Le fait d'y recourir, associé à la contrainte et conditionné par la persécution - mais strictement limité nous le verrons -, transparaît néanmoins des toutes premières recommandations adressées aux fidèles, appelés à maintenir le culte en des endroits retirés :

Si durant le jour tous les fidèles ne peuvent pas s'assembler, il faut que le chef de famille fasse avec sa famille deux exercices de piété [...] $\&$ qu'il reçoive autant de frères qu'il pourra [...]. Mais autant qu'il se peut, il faut que tous les fidèles s'assemblent; il faut qu'ils le fassent

48. Mémoires de Bonbonnoux, op. cit., p. 7, 88-89, 90-94, 99.

49. Ch. Dardier, La Vie des étudiants au Désert, op. cit., p. 37, 48-49.

50. Cf. Ibid., p. 31, 36-37, 73-75; BGE, Ms Court n 17 B : Mémoires de M. Fauché, $\mathrm{f}^{\circ} 6 / \mathrm{p} .4 \mathrm{v}^{\circ}$ et $\mathrm{f}^{\circ} 8 / \mathrm{p} .5 \mathrm{v}^{\circ} ;$ Mémoires de Jean Martel du Dauphiné, $\mathrm{f}^{\mathrm{o}} 63$ 78/p. 33-40; Mémoire de Lavérune dit Gavanon, fo95/p. 49. 
de nuit, s'ils ne peuvent pas le jour, dans les caves, ou à la campagne, $\mathrm{s}^{\prime}$ ils ne peuvent pas ailleurs ${ }^{51}$.

Pierre Jurieu appelle en 1687 au secret des cœurs : « quand vous ne pourrés vous assembler pour prier Dieu avec vos freres, vous avés vos cabinets dont vous pouvés faire des temples, \& vos cœurs dont vous ferés des sanctuaires $\&$ des autels ». Invitant les réformés de France à se retirer des lieux où règne la persécution, le pasteur de Rotterdam les conjure en 1688 de résister «par des assemblées publiques ou particulières; cachées si vous ne pouvez faire autrement » et leur fixe comme devoir de maintenir les réunions « dans les maisons, dans les mazures, dans les bois $\&$ partout où vous pourrez $^{52} »$. Quant au pasteur Pierre Encontre, réfugié en Hollande, il exhorte les fidèles à conserver précieusement leurs livres de dévotion et de controverse - « sauvez les en les cachant et les derrobant a l'inquisition de vos persecuteurs ${ }^{53} »-$, tout en les appelant à maintenir l'union, fût-ce en secret :

Ayez soin dentretenir des correspondances entre vous, connaissezvous les uns les autres à sçavoir tous ceux qui ayment verite a dessein de ne l'abandonner jamais; si vous pouvez dans quelque temps vous assembler secretement la nuit dans des lieux retirez de vos maisons faites le pour y lire la parole de Dieu [...] surtout pour prier $^{54}$.

Utilisé d'emblée par les pasteurs du Désert, le secret innerve la réglementation synodale. Dès 1715 , les synodes décident de convoquer les assemblées « avec toute la prudence et le secret possibles $^{55} »$. Cet impératif de prudence et de sûreté recourant à la confidentialité autant qu'à l'anonymat structure toute la réorganisation spirituelle, disciplinaire et ecclésiale. Selon les provinces, l'exigence formelle de l'usage du secret apparaît jusqu'en septembre $1761^{56}$. La plupart des décisions visent à préserver le secret

51. Instruction pour les exercices de piété des Églises Réformées de France qui sont sous la croix in C. Brousson, Lettres et opuscules, op. cit., p. 219-220.

52. P. Jurieu, Lettres pastorales, op. cit.: lettres XVIII (1 ${ }^{\text {er }}$ mai 1687), p. 140 et XIV (15 mars 1688), p. 108, 110.

53. A nos freres quy gemissent sous la captivité de babylon. A quy nous souhaitons paix et miséricorde de la part de Dieu (25 octobre 1685), in P. Encontre, Trois lettres du Refuge, op. cit., p. 7.

54. Ibid., p. 8.

55. Synode du 21 août 1715 (art. III) : Les Synodes du Désert, op. cit., t. I, p. 2.

56. Singulièrement en Bordelais où les assemblées se tenant dans la ville exigent des précautions strictes (ibid., t. II, Appendice, p. 506) et à La Rochelle 
des initiatives : convocation des assemblées de huit jours en huit jours et «peu [...] dans un même endroit » pour éviter toute localisation, absence de signature des députés des synodes «crainte que si les pièces signées venaient à se perdre ou à tomber entre les mains des ennemis, on ne [leur] fît [...] des affaires fâcheuses ", convocation des réunions avec circonspection «pour ne donner aucunes lumières ni porter aucun préjudice [aux assistants]», durée limitée du culte et placement obligatoire de sentinelles pour éviter d'être repéré, silence imposé à tout fidèle venant à être interrogé par des particuliers sur les réunions de prière, dépôt « dans un lieu de sûreté » des actes paroissiaux et des actes des synodes nationaux. Toute liaison avec le troupeau passe par le filtre des anciens, chargés d'avertir et d'éviter le déplacement inutile des fidèles, les mouvements de foule et les transferts d'un mandement à l'autre. Intermédiaires privilégiés de ces dispositions confidentielles, les anciens doivent désigner les personnes et les familles de confiance sur lesquelles adosser l'activité pastorale ${ }^{57}$. Toute contravention à la prudence peut valoir au téméraire - « indigne de secours »-1'abandon des siens, et au pasteur la démission de sa charge ${ }^{58}$; tout dévoilement entraine sanction :

Pour ce qui regarde [...] la personne interrogée, se prenant bien garde de ne rien dire des autres que les persécuteurs voudraient rechercher, puisqu'un vrai fidèle, en même temps qu'il doit être véritable \& sincère, doit garder un profond silence sur tout ce où Dieu n'est pas glorifié [...] \& qui pourraient attirer des persécutions aux autres membres de Jésus-Christ. Et si quelqu'un agissait d'une autre

où la règlementation des Statuts des Comitants du 11 septembre 1761 requiert (art. 47) que « tout Comitant promet[te] sur sa parole d'honneur de garder un secret inviolable sur toutes les affaires qui seront traitées dans les assemblées et de n'en donner aucune connaissance au gens du dehors » : ibid., t. II, p. 247.

57. Sur l'ensemble de ces dispositions liées à la pratique du secret, $c f$. les synodes provinciaux du Dauphiné du 22 août 1716 et du Languedoc du 2 mars 1717 (art. additif V); synode provincial des Cévennes du 21 novembre 1718 (complément Ms Court $\mathrm{n}^{\circ} 46$ ) et du 20 septembre 1720 (art. II); synodes provinciaux du Vivarais du 26 juillet 1721 (art. IV et XVI) et du 21 juin 1725 (art. XI, XXI et XXII); synode national du Vivarais du 16 mai 1726 (art. V, VI, IX, XI); synode national des Cévennes des 11-18 septembre 1748 : ibid., t. I, p. 6, 14, 19, 25, 26, 46, 48, 55-57, 273.

58. Synodes provinciaux du Dauphiné du 22 août 1716 et du Languedoc du 2 mars 1717 (art. additifs III et IV) : ibid., t. I, p. 6. Décision réitérée dans les actes du synode provincial du Vivarais du 21 juin 1725 (art. XVIII) et du synode national du Vivarais du 16 mai 1726 (art. XXII) : ibid., t. I, p. 47, 60. 
manière, il sera regardé comme lâche \& apostat par égard à l'Eglise, $\&$ comme traître [...] \& en cette qualité poursuivi par toutes voies ecclésiastiques $^{59}$.

Le secret est encore formellement prescrit - singulièrement en Guyenne - en décembre 1754 : «Il est enjoint à Messieurs les anciens de garder un secret inviolable concernant les retraites du pasteur; ceux qui le violent [...] seront censurés ${ }^{60}$. » De même, il exigeait que les « anciens garderont un secret inviolable sur tout ce qui sera mis en délibération dans les tribunaux ecclésiastiques, sous peine aux contrevenants d'être déposés de leur charge pour toujours $^{61} \gg$. Objet de trois articles spécifiques, le secret vaut, en matière de culte, pour l'ensemble de la communauté :

Reconnaissant qu'après le secours de Dieu le soutien des églises oppressées est le secret, nous exhortons fortement les fidèles de le garder inviolablement, concernant les assemblées, les personnes qui s'y rendront, le lieu où elles se tiendront, etc.; ceux qui ne se conformeront pas à ces avertissements seront poursuivis [...] et, même exclus des saintes assemblées ${ }^{62}$.

Il apparait de nouveau en 1758 dans les délibérations du Colloque de Saintonge recommandant «à toutes les églises un secret inviolable sur toutes les affaires » concernant les réformés ${ }^{63}$. Silence et secret filtrent aussi des prescriptions ponctuelles, à l'instar de celles du pasteur Pagon exigeant des membres du consistoire amenés à s'assembler dans des maisons particulières « le secret le plus absolu» y compris envers leurs familles ${ }^{64}$. Le secret ne se limite pourtant pas aux assistants. Les directeurs de conscience en usent pour eux-mêmes.

59. Synode national du Vivarais du 16 mai 1726 (art. XXII) : Les synodes du Désert, op. cit., t. I, p. 60.

60. Colloque du Bordelais du 17 décembre 1754 (art. 6) : Les synodes du Désert, op. cit., t. II, p. 47.

61. Ibid., (art. 25), t. II, p. 49. Un avertissement avant sanction est notifié en avril 1756 : ibid., t. II, p. 74.

62. Ibid., (art. 18), t. II, p. 48.

63. Colloque de Saintonge du $1^{\text {er }}$ et 2 décembre 1758 (art. 15) : ibid., t. II, p. 149.

64. L.-M. de Meschinet de Richemond, L'Église sous la Croix, op. cit., p. 19 cite l'une des mesures consignées dans un règlement de soixante-quatorze articles, révisé au mois d'octobre 1761. $C f$. aussi BPF, Coll. Fraissinet-Vielles $\mathrm{ms} \mathrm{n}^{\circ} 873^{6}$, chem. 5, témoignant de prédicants « exigeant des auditeurs le secret de ne se point découvrir [sur les assemblées], de mourir plutôt ». 
De fait, sans être rare ni singulier, l'usage du secret est polymorphe. Tout un ensemble de mesures préventives encadrent sa pratique ordinaire. Précaution et confidentialité - préalables ou connexes - en forment les frontières fluctuantes. La plupart des prédicants font preuve de mobilité, se déplacent à la clarté de la lune en privilégiant les chemins de traverse, usent de déguisements ou changent fréquemment d' « équipage » et de lieu de retraite. Souhaitant le plus souvent garder l'anonymat, évitant de signer ou exigeant de n'être point nommés, ni d'exposer leurs hôtes ou les destinataires de leurs correspondances, ils usent de pseudonymes et de l'adresse du « Désert », modifient leurs postes restantes, se tiennent souvent cachés jusqu'au soir dans leur gîte avant d'entamer leurs marches à « petits bruits ${ }^{65}$ », dissociées de celles des fidèles ${ }^{66}$, en prenant soin de masquer leur itinéraire : «il importe qu'on ne me nomme point, $\&$ que personne ne sache où je vais, ni où je suis » écrit Brousson en 1695 ; « je change très souvent de retraite. Je ne marche que de nuit, et ne me fais jamais accompagner, en sorte qu'il n'y a que les gens de la maison où je suis logé, qui sachent où je suis ", écrit encore Lombard durant l'été $1761^{67}$. Des conférences «secrètes" pour gagner le Refuge, organiser la surveillance de la jeunesse et remédier aux succès des séductions catholiques jalonnent la résistance pastorale ${ }^{68}$. Bien que l'entrée dans les villes comporte toujours des risques, plusieurs y organisent des réunions de prières, à l'instar de Court dans les caves de la cité d'Anduze « après en avoir bien bouché les soupiraux avec des sacs remplis de laine ou avec des matelas ${ }^{69} »$.

65. A. Court, Mémoires, op. cit., p. 84.

66. $\mathrm{BPF}, \mathrm{Ms} 1058-\mathrm{X}$, non folioté : Mémoire des protestans de la généralité de Montauban, 1744-1746.

67. Sur l'ensemble de ces pratiques, $c f$. C. Brousson, Lettres et opuscules, op. cit., p. 289, 291-300, 310, 324-326; Ch. Dardier, La vie des étudiants au Désert, op. cit., p. 10, 11, 14, 49, 62-63, 73-76; BGE, Ms Court n 17 B : Mémoires de M. Fauché, $\mathrm{f}^{\circ} 10 / \mathrm{p} .6 \mathrm{v}^{\circ}$; Mémoires de Jean Martel du Dauphiné, $\mathrm{f}^{\circ} 63-78 / \mathrm{p}$. 33-40. Sur l'usage des signatures, très variable selon les acteurs indépendamment de la période, la restriction valait surtout pour les députés des Églises, moins pour les pasteurs du Désert: A. Court, Mémoires, op. cit., p. 95.

68. A. Court, Mémoires, op. cit., p. 92; BPF, Coll. Coquerel, ms 302 (Papiers Paul Rabaut): Avis important à Messieurs les pasteurs et les anciens des églises réformées de la province de Languedoc, s.d. [années 1730], f 125-127 : « le secret étant important dans cet afaire $»$.

69. A. Court, Mémoires, op. cit., p. 85. 
Tout un vocabulaire secret s'élabore. Si, en matière de convocations des assemblées et de coordination des initiatives, l'oralité prévaut souvent, les correspondances conservées montrent que plusieurs ministres opèrent un codage de leurs missives : usage de noms d'emprunts et d'expressions camouflant leur identité (parfois celle des fidèles ou des représentants du pouvoir), brouillant les toponymes (lieux de résidence et de réunion), masquant les activités (la « foire », le « sacré collège », la « classe » ou l'annonce d'un « mariage » servant notamment à désigner la tenue prochaine d'un synode). Sans recourir au lexique complexe du ministre Pougnard, élaboré en 1760 à l'attention des pasteurs du Désert du Poitou (qui utilise aphérèses, dérivations et métathèses), plusieurs prédicants du royaume et proposants du séminaire de Lausanne usent, au moins ponctuellement, d'anagrammes et plus souvent d'une langue figurée - à tout le moins d'un langage de convention - pour se garantir des poursuites et éviter de mettre en danger l'activité de leurs confrères au cas où leurs lettres seraient interceptées par les autorités ${ }^{70}$. De manière pratique, c'est aussi en secret que se multiplient les écoles - buissonnières et ambulantes - et les maisons d'oraison, que se créent les séminaires de formation des pasteurs - séminaires internes en Languedoc et Dauphiné (en 1745 et 1757) puis seulement lausannois - et que s'établissent les réseaux épistolaires entre le royaume et le Refuge. C'est d'ailleurs bien « au secret exact qui s'observe parmi les protestants » que les intendants - singulièrement celui de La Rochelle en 1752 - attribuent l'insuccès de leurs démarches.

De même s'élaborent les routes d'exil, les chemins de retour, les filières de propagande fournissant catéchismes, sermons, Bibles, livres de piété et instructions de Pictet, Saurin, Drelincourt, Ostervald, édités à l'étranger (Provinces-Unies, Pays-Bas espagnols, Suisse) ou publiés en France (Orléans, La Rochelle, Toulouse, Lyon) en des lieux d'impression fictifs, élaborés en chambre, dans des caves, des entrepôts ou des ateliers secrets, transportés dans des caisses étiquetées xuvres de Molière ou cachés dans des tonneaux

70. BPF, ms 224 ${ }^{1-2}$ : Vocabulaire des prédicants du Désert; Théodore Maillard, «Vocabulaire secret des pasteurs du Désert en Poitou, pour la sécurité de leur correspondance », BSHPF, 38 (1889), p. 257-270; Pierre Rézeau, « Vocabulaire secret d'un pasteur du Poitou (vers 1770) », Revue de la Société d'études folkloriques du Centre-Ouest, 128-130 (1986), p. 119-144, 181-197, 261-269. 
de poix, des caisses de liqueurs, des boîtes d'amandes ou d'olives, distribués sous le manteau par des colporteurs ou clandestinement dans les foires ${ }^{71}$. Ces pratiques secrètes empruntées par les protestants foisonnent. À l'évidence cependant, ces déclinaisons relèvent des seuls registres organisationnel et préventif. Ce qui n'ôte rien à l'importance de leur rôle, mais suggère déjà de puissantes limites.

\section{AUX SOURCES D'UNE IDENTITÉ CONFESSIONNELLE RÉFORMÉE}

\section{Secret et clandestinité : ferments d'une cohésion communautaire}

Moyen privilégié utilisé pour rassembler les fidèles, le secret est un creuset de solidarités. Il n'a pas pour seule fonction de braver, dans la clandestinité, une législation oppressive. C'est lui qui, en réseau, sert à l'union d'un peuple disséminé. C'est en partie sous le sceau du secret que se retrouve et s'incarne la communauté de chrétiens, appelés à se reconnaître dans cette condition d'accès sélective, partagée en petit nombre. Bien sûr, il agit à des échelles variables : des plus petites cellules qu'illustrent la conviction intime et le culte domestique, au culte de société réuni entre proches voisins (comités et sociétés), et jusqu'à l'assemblée communautaire clandestine réunissant parfois plusieurs centaines de fidèles. Agissant en diverses sphères, le secret crée, dans et par la confidentialité, les conditions d'appartenance et de reconnaissance communautaire. En ce sens, il agit comme un puissant ferment identitaire valorisant un particularisme confessionnel. Là, en clandestinité, se révèle le frère, se dévoile l'union, se tisse une identité en partage, se confesse un malheur, se trament des espoirs, s'affirme une conviction et se scelle une résistance. Là, à l'écart, se noue une entité singulière forgée par l'épreuve.

Tout au long du siècle, c'est en partie par le biais du secret que se met en place une « ecclésiologie de crise » prenant le relais de l'orga-

71. Dominique Verry, «André Degouin, imprimeur libraire lyonnais condamné pour production d'ouvrages protestants (1734-1735)» et Yves Krumenacker, «La circulation clandestine des livres protestants au XVIII" siècle », in G. Artigas-Menant, A. McKenna (dir.), Protestants, protestantisme et pensée clandestine, op. cit., p. 71-84 et p. 85-101 ; Françoise Weil, « Les livres persécutés en France de 1720 à 1770 », in O. Bloch, Censure et clandestinité aux XVII et ${ }_{X V I I I}{ }^{e}$ siècles, op. cit., p. 263-269; Myriam Yardeni, "Contrebande et circulation des livres religieux protestants en France au XVIII" siècle », in Id., Le Refuge huguenot : assimilation et culture, Paris, H. Champion, 2002, p. 177-186. 
nisation qui prévalait sous l'Édit de Nantes ${ }^{72}$. De cette résistance dissimulée naît la réponse à l'un des principes fondateurs des Églises Réformées de France : le devoir de s'assembler en dépit des interdits stipulés par l'article 26 de la Confession de foi de La Rochelle : « Nul ne se doit retirer à part et se contenter de sa personne, mais tous ensemble doivent garder et entretenir l'union de l'Église, et ce en quelque lieu où Dieu aura établi un vrai ordre d'Église, encore que les magistrats et leurs édits y seront contraires ${ }^{73}$. » À ce titre, le secret qui prédomine dans la convocation des assemblées est paradoxalement le moyen de redonner aux fidèles une Église visible et de témoigner, en miroir, de sa vitalité. De ces unions cachées formant germes d'Églises appelées à s'institutionnaliser pour devenir à proprement parler les Églises du Désert ${ }^{74}$, il constitue le liant et forme l'un des jalons du redressement calviniste. Inextricablement lié à l'expérience de la clandestinité, il accompagne le processus d'édification et préserve l'alimentation spirituelle des proscrits. L'usage n'en reste pas moins strictement circonscrit. La pratique même du secret est polémique et ne saurait s'imposer en tous registres. Il est banni de certains domaines, au risque du parjure, sans compter que le mode du secret est sévèrement critiqué.

\section{Altérités, dissonances, déviances}

L'illicite suscite de nombreuses tensions intra-confessionnelles. La dissimulation, favorable au nicodémisme, est jugée contraire à la posture du vrai fidèle parce que refuge des timides, des fourbes et des accommodeurs, vomis de la bouche de Dieu (Ap 3,16-17) ${ }^{75}$. La clandestinité est aussi sujette à sédition : l'activité spontanée des premiers prédicants du Midi (appréhendée par certains comme une usurpation); l'appel au rassemblement des «Églises interdites »

72. H. Bost, « Le Désert des huguenots : une poétique de l'épreuve », art. cité, p. 182.

73. Principe que 1'«on observera religieusement» écrit Brousson dans l'article 3 du Projet des Réformés fait au mois de May 1683 pour la conservation de la liberté de leur conscience \& de l'Exercice public de leur Religion éd. in Avertissement aux Protestans des provinces (1684), présenté par Élisabeth Labrousse, Paris, PUF, 1986, p. 29. Devoir dont l'Apologie, op. cit, p. 7, 13 valorise toujours la défense et la primauté en 1745 .

74. H. Bost, « Le Désert des huguenots : une poétique de l'épreuve », art. cité, p. 203.

75. P. Jurieu, Lettres pastorales, op. cit. : lettre XXIII ( $1^{\text {er }}$ août 1688), p. 167. 
lancé en 1683 par Brousson (assimilé à un acte de défi envers le pouvoir temporel); la théologie née au Désert inspirée par une lecture apocalyptique des temps associée aux semonces velléitaires de Jurieu, de même que l'enthousiasme prophétique (considéré comme un abâtardissement de l'Évangile ${ }^{76}$ ) et l'acte d'insubordination camisard (venu ruiner le principe revendiqué de loyalisme réformé), ont fait de la clandestinité une matrice de déviances aux yeux des tenants de l'orthodoxie calviniste. La scission n'épouse pas la frontière entre prédicants du royaume et ministres du Refuge. Chaque camp a ses défenseurs et ses détracteurs. Le Désert compte lui aussi, en la figure de Court - et déjà de Brousson -, ses partisans de l'ordre, soucieux de répondre du soupçon, sinon de l'accusation, de rébellion. L'ensemble de ces dérives n'est pas pour rassurer sur la menace de ces unions clandestines, y compris parmi les artisans de la restauration, eux-mêmes longtemps contraints d'agir de manière cachée pour redresser leurs Églises, et exposés à une communauté façonnée par la clandestinité, qui a fait l'expérience d'une liberté exigeante et d'une piété combative en rupture avec le langage de fidélité au souverain, sinon en « rupture de ban » avec ses cadres ${ }^{77}$. Le retour à la normalisation, face à ce que E.-G. Léonard a nommé « une conception mosaïque des rapports avec $\operatorname{Dieu}^{78} »$, ne se fait pas sans oppositions schismatiques, tant le recours à l'illicite fut le terreau d'une refonte d'envergure qui, autonome et affranchie à ses débuts des structures disciplinaires traditionnelles, modifia les rapports de force entre fidèles et directeurs de conscience. Foyer d'audaces - principalement dans le Midi huguenot -, la clandestinité recèle la transgression. Il y aura toujours urgence à en sortir.

\section{De la prudence au cour fardé : le seuil de l'« hommage découvert »}

D'un point de vue théologique, le secret est matière à controverse : inhérent à la religion où tout est révélation et mystère, il porte en lui le risque de la falsification. Du moins les réformés lisent-ils

76. Mémoires de Bonbonnoux, op. cit., p. 106-107.

77. Daniel Vidal, L'Ablatif absolu, théorie du prophétisme, Paris, Anthropos, 1977, avant-propos.

78. Émile-G. Léonard, «Les Assemblées au Désert. Caractères, adversaires et conséquences », BSHPF, 87 (1938), p. 484. 
dans la Discipline du secret - terme apparu en 1677 - un usage proprement romain visant à légitimer, à couvert de la Tradition et d'une prétendue autorité cachée, un dogme et des pratiques sans fondements scripturaires. Cette discipline, liée en 1685 à Schelstrate (De disciplina arcani) qui l'inscrit dans les coutumes de l'Église primitive, s'attire la réfutation du parti protestant - notamment de Casaubon et Daillé - qui en démontre l'absence dans les œuvres patristiques. Tandis que les catholiques fondent leur argumentation sur la fréquente répétition dans les évangiles du mot mystère, interprété comme synonyme de choses secrètes à garder pour n'être révélées qu'aux initiés, les réformés postulent que le mystère ne signifie pas une chose à cacher mais une chose cachée auparavant et révélée par Dieu aux hommes. Constituant un contresens biblique - la propagation de la doctrine de Jésus n'étant pas affaire d'initiation mais annonce -, le secret demeure pour eux conceptuellement lié à une usurpation servant une prétention catholique à ériger ses préceptes additifs en doctrine traditionnelle ${ }^{79}$. La défiance n'est pas que théorique. L'édification de la nouvelle Jérusalem ne peut souffrir la dissimulation.

En ces temps d'oppression redoublée, la contradiction entre impératif de survie et exigence de confesser publiquement sa foi - sous peine d'être renié par Dieu au Jugement dernier (Mt 10,33) - n'est qu'apparente. Nulle ambiguïté ne subsiste dans les directives pastorales : la prudence ne doit pas dégénérer en timidite $^{80}$. Le secret qui vaut pour la préservation du troupeau ne saurait s'appliquer à ce qui a trait à la gloire de Dieu. Le Christ a « parlé ouvertement » et n'a rien dit « en cachette» (Jn 18,21). Les exhortations se conforment

79. Charles Heim, Recherche sur la discipline du secret, Genève, P.-A. Bonnant, 1843; André Francou, Étude sur l'origine et la nature de la discipline du secret, Strasbourg, Berger-Levrault, 1853. Cette position protestante valorisant l'annonce se trouve explicitée dans un sermon de Timothée Delon, Le secret de piété, Montauban, P. Coderc, 1638, prêchant que la gloire de Dieu est de publier ses secrets, révélés par la venue du Christ et la divulgation de sa Parole. La Loi, naturellement fichée au cœur des hommes, est illuminée par la « divine clarté » (cf. p. 20, 24-25, 113, 118-119). Le protestantisme privilégie un christianisme de l'intime à un christianisme du secret: Jacques Guin (dir.), Le secret, Paris, Van Dieren, 2007, introduction, p. 8. Pour une approche théologique du secret messianique et la prévalence d'un Dieu révélé dans le calvinisme, voir dans ce même ouvrage, les articles de Raphaël Picon, « Dieu et le secret », p. 9-22 (particulièrement p. 13-16, 19) et Laurent Gagnebin, « Le protestantisme et le secret », p. 69-82.

80. Lettre aux pasteurs de France, refugiez dans les Etats protestans, éd. in C. Brousson, Lettres et opuscules, op. cit., p. 38. 
à l'Évangile exigeant que la Parole et la reconnaissance de Dieu se manifestent «dans la lumière » et sur le « haut des maisons » (Mt 10,26). N'est exigé un «profond silence [que] sur tout ce où Dieu n'est pas glorifié ${ }^{81} »$. Le recours au secret, utilisé comme moyen de préserver la communauté, ne saurait être subterfuge de foi, dissimulation de croyance, celle-ci ne pouvant s'accommoder du compromis, la vérité devant être soutenue ostensiblement. En la matière, les exigences sont claires : « il ne faut point cacher nos sentimens il faut etre toûjours prest a confesser la verité par tout» et dire «sans misteres" l'aversion pour le culte catholique ${ }^{82}$. La tension prudence/confession est constante, mais la foi en est le critère. S'il y a lieu de s'assembler secrètement pour préserver le culte, il demeure impératif de s'exposer aux souffrances plutôt que de renier Dieu : les «chiens müets » et les «dissimulateurs » faisant «les papistes devant les papistes » s'exposent à être abandonnés de Dieu ${ }^{83}$ (Ex 20,5). Les "gémissements secrets» ne servent de rien $^{84}$, les «mouvements foibles et secrets " sont ceux des hypocrites, raille Basnage ${ }^{85}$. Il y a exigence, s'accordent à répéter les ministres, à louer Dieu hautement à la face des hommes ${ }^{86}(2 \mathrm{~S}$ 12,12), fût-ce d'abord seulement entre frères : car comment croire et entendre Dieu sans le proclamer, interroge Court en référence à Paul $(\mathrm{Rm} \mathrm{10,14)}$ ? À l'appui de l'Apôtre (Rm 10, 9-10), Jurieu cerne les contours de la dissimulation coupable et rappelle le devoir de confession de bouche :

Nous n'avons point appris que Dieu reçoive [...] les hommages de ceux qui luy disent : [...] Je confesse que je suis un dissimulateur $[\ldots]$ mais [...] prenés mes bonnes œuvres pour compensation de la fausse profession que je fais, \& des mesures criminelles que je garde avec l'erreur. Dieu, dis-je, ne souffre point de pareils traittés. [...]. La justification se donne au cœur, \& le salut à la bouche [...], mais ta bouche, son silence $\&$ le defaut de confession te damneront selon la sentence de l'Apostre [...]. Nous recevons de Dieu deux bien faits, l'un caché,

81. Acte du synode national du Vivarais du 16 mai 1726 (art. XXII) : Les synodes du Désert, op. cit., t. I, p. 60.

82. P. Encontre, Trois lettres du Refuge, op. cit., p. 6.

83. Ibid., p. 8-9, 11.

84. P. Jurieu, Lettres pastorales, op. cit. : lettre XV (1 ${ }^{\mathrm{er}}$ avril 1687), p. 126.

85. [Jacques Basnage], Considérations sur l'état de ceux qui sont tombez ou Lettre à l'Eglise de ${ }^{* * * * *}$ sur sa chute, Rotterdam, Abraham Acher, 1686, p. 397-398.

86. C. Brousson, Lettres et opuscules, op. cit., p. 195 ; P. Jurieu, Lettres pastorales, op. cit. : lettre XIV (15 mars 1688), p. 108. 
l'autre public \& découvert : le bien fait caché c'est la justification, le bien fait decouvert, c'est le salut. La justification se fait dans les secrets du cœur \& le salut se donnera au dernier jour à la veue de toute la terre. S. Paul nous apprend que pour le bien fait caché Dieu nous demande le cœur qui est aussi caché, de cœur on croit pour estre justifié; \& pour le bien fait découvert, sçavoir le salut, il nous demande un hommage découvert, de bouche on fait profession pour estre sauvé. [...] Comment aussi pretendriés vous separer ces deux hommages la foy $d u$ cœur, \& la confession de la bouche? Ne vous flattés pas dissimulateurs vôtre estat est mortel, vôtre cœur sans confession ne vous justifiera pas \& ne vous sauvera pas : au contraire vôtre cœur vous condamne \& se levera en jugement contre vous ${ }^{87}$.

Les « obstacles » ont imposé l'usage du secret mais celui-ci doit servir une exigence : maintenir les «sentiments de la Religion » en préparant la venue du règne de Dieu ${ }^{88}$. Prudence et secret ne sont tolérés que pour se mettre à l'abri des ennemis et des persécuteurs $^{89}$, mais ne sauraient être reniement au moment de l'épreuve. Analogue à l'attitude christique, le secret n'est requis que lorsque tout exprimer expose à la répression, à l'imprudence des zélotes, à la haine des Pharisiens. Que l'on ne s'y trompe pas, le culte au Désert n'est pas dissimulation mais réactivation de l'Alliance. Pour les réformés, le secret ne répond qu'aux périls encourus et ne procède que d'un temps de captivité. Il est provisoire, dans l'attente que Dieu rende aux fidèles la liberté de le servir publiquement. Dans cette perspective, toute pratique secrète n'est pas interdite, pourvu qu'elle n'attente pas à la confession de Jésus-Christ, car en ce registre il est exigé de souffrir la persécution - annoncée par le Fils (Jn 15,20-21) et où «brille la foi du fidèle » dit Jurieu - plutôt que de céder à la Bête et de tenir ses choix secrets ${ }^{90}$. Réserver l'intérieur à Dieu ne suffit pas, au risque de provoquer sa jalousie ${ }^{91}$. À rebours du secret demeure l'« obligation indispensable » de pro-

87. P. Jurieu, Lettres pastorales, op. cit.: lettre XXIV (15 août 1688), p. 175. $C f$. aussi [A. Court], Apologie, op. cit., p. 17.

88. [A. Court], Apologie, op. cit., p. 5.

89. A. Court, Mémoires, op. cit., p. 68.

90. Synode du Vivarais, 21 juin 1725 (art. XXI) : « on sera obligé de déclarer la vérité, en ce qui regarde le particulier et tout ce qui tend à la gloire de Dieu \& à l'édification de son Eglise, mais [...] sur tout ce qui ne tend pas à ce but on gardera un profond silence, n'étant pas obligé ni par les lois naturelles ni par celles de l'Evangile de révéler ce qui peut être préjudiciable à nos frères » : Les synodes du Désert, op. cit., t. I, p. 48.

91. P. Encontre, Trois lettres du Refuge, op. cit., p. 29. 
duire la foi « au dehors » et d'en faire « profession publique ${ }^{92}$ ». Ainsi, quand bien même l'esclavage des temps exigerait de la manifester à « l'insu des ennemis », elle doit être publique, c'est-à-dire effectuée en commun parmi les proscrits. De même, à crime public, réparation publique: "Vôtre penitence ne peut être variable que par le raport qu'elle aura avec vôtre crime, vous avez renié publiquement J. C. il faut le confesser de la même sorte [...] vous avez contristé l'eglise de Dieu par un grand blaspheme il faut la réjouir par une confession eclatante ${ }^{93}$. » Le redressement d'Israël passe par l'hommage découvert qui a valeur d'édification mutuelle. Fût-ce en retrait, la lumière divine ne doit pas être cachée sous le boisseau mais être placée sur un chandelier (Mt 5,15).

Le recours au secret n'est donc que transitoire et partiel. Pourtant, ce passage contraint mènera à la délivrance, par la soif de témoigner qu'il recèle : « lassez de porter une conscience dans les fers \& de dissimuler leurs sentimens, ils éclateront publiquement » assure Jurieu $^{94}$, parole qui se vérifie au-delà de la détonation camisarde. Cet usage ne peut être autre chose qu'une précaution pour éviter la saignée du troupeau et la trahison des faux-frères. S'il peut constituer une forteresse spirituelle inviolable, à même de protéger l'intimité de la croyance, il demeurera indéniablement, sous la plume des pasteurs, un remède bancal face à la figure de confesseur, mort précisément pour ne pas avoir voulu dissimuler. Rien ne sert de s'exposer gratuitement, mais la résistance par la profession publique de sa foi - dans les assemblées mutuelles (par déclaration de fidélité, rétractation des abjurations, réparation solennelle du péché de conversion) ou par le martyre - demeure la plus digne. S'il est préférable de se tenir en retrait plutôt que de participer à un culte catholique idolâtre, la prosternation sous le couteau vaut mieux que le secret pernicieux de la foi, semblable au cœur fardé qui « retient la vérité en injustice ${ }^{95} \gg$. D'autant que glorifier Dieu publiquement est

92. [A. Court], Apologie, op. cit., p. 18.

93. Lettre pastorale aux protestans de France quy sont tombez par la force des tourmens (26 octobre 1685): P. Encontre, Trois lettres du Refuge, op. cit., p. 18. Cf. aussi P. Jurieu, Lettres pastorales, op. cit. : lettre XIV (15 mars 1688), p. $110,111$.

94. P. Jurieu, Lettres pastorales, op. cit. : lettre XIV (15 mars 1688), p. 109.

95. Ibid.; [J. Basnage], Considérations sur l'état de ceux qui sont tombez, op. cit., p. 354. 
considéré comme la seule façon de détromper et de déconcerter les persécuteurs ${ }^{96}$.

Au-delà des fondements scripturaires, le souci de visibilité qui accompagne ce redressement huguenot clandestin forme un seuil supplémentaire à l'usage du secret. S'il bute sur des principes théologiques forts, le secret se heurte aussi à une posture loyaliste qui valorise la transparence.

Tout ne se fait pas en secret, nous l'avons dit. Le phénomène n'est pas affaire de temporalité. Il anime de bout en bout les démarches pastorales. Tout au long de la période de répression (notamment en 1683, 1684, 1698, 1713, 1744, 1752, 1763), le recours aux plaintes, placets, épîtres et requêtes adressées au roi, à ses représentants ou au clergé atteste de la volonté des réformés de faire connaître leur situation accablante - sinon absurde - et de faire entendre à la Cour leurs revendications ${ }^{97}$. Les déclarations publiques et les rassemblements en plein jour, les psaumes chantés à haute voix par les fidèles accompagnent, avec plus ou moins d'à-propos, cette militance déclarée en quête d'un droit à la liberté de conscience ${ }^{98}$. D'ailleurs, il n'est pas seulement requis des fidèles de résister à l'interdit : ils sont appelés à valoriser ouvertement le sens de leur désobéissance. En cas d'arrestation, instruction est donnée de « supplier humblement » les magistrats du roi de « considérer» le devoir de chrétien auquel se conforment les protestants et de « représenter avec humilité » leur soumission première à $\operatorname{Dieu}^{99}$ - injonction réitérée dans les synodes. La formule de 1725 conjugue obligation de résistance et protestation résolument loyale :

96. P. Jurieu, Lettres pastorales, op. cit. : lettre XXIII ( $1^{\text {er }}$ août 1688), p. 167.

97. Cf. Claude Brousson, Estat des Réformez en France, Cologne, Pierre du Marteau, 1684; Id., Lettres au clergé de France assemblé à Paris en l'année 1685, Au Désert 1685; Id., Requestes envoyées au Roy de France par ses sujets protestans, op. cit.; Jean Claude, Les plaintes des Protestans cruellement opprimez dans le Roiaume de France, Cologne, Pierre Marteau, 1713; Synode national du Bas Languedoc, 18 au 28 août 1744 (art. III et IV): Les synodes du Désert, op. cit., t. I, p. 189; Hubert Bost, «Un "traité sur la tolérance" clandestin : la Requête des protestants par La Beaumelle en 1763 ", in G. Artigas-Menant, A. McKenna (dir.), Protestants, protestantisme et pensée clandestine, op. cit., p. $119-138$.

98. BGE, Ms Court $\mathrm{n}^{\circ} 17 \mathrm{~B}:$ Mémoire de M. Faure, $\mathrm{f}^{\circ} 164 / \mathrm{p} .83 \mathrm{v}^{\circ}$; Relation des principaux faits qui sont arrives dans cette province du Dauphiné au sujet de la Religion Protestante depuis la cassassion de l'Edit de Nantes, $\mathrm{f}^{\circ} 177-178 /$ p. $90-90 \mathrm{v}^{\circ}$.

99. C. Brousson, Lettres et opuscules, op. cit., p. 195-197. 
Sur la proposition qui a été faite de quelle manière doivent se conduire les fidèles qui viennent à être arrêtés [...] la compagnie a délibéré que, si ceux qui les interrogent sont de simples particuliers qui n'en aient aucun ordre de la part du Roi, il ne leur sera rien répondu; au contraire que si c'est un magistrat ou plusieurs représentant la personne du Roi qui le fassent, on sera obligé de déclarer la vérité, en ce qui regarde le particulier et tout ce qui tend à la gloire de Dieu \& à l'édification de son Eglise [...]; que, si quelqu'un était assez faible ou méchant que de cacher le moindre des articles qui pourraient contribuer à ce but, [il] sera déclaré pour ce qui regarde l'Eglise traître et apostat $\&$ pour ce qui regarde l'Etat rebelle \& séditieux ${ }^{100}$.

Valorisé pour sécuriser les modalités de réorganisation, le secret est fréquemment et délibérément éventé afin de ne pas donner prise aux accusations de complot, de distinguer la résistance de toute velléité séditieuse et de porter hautement la cause ${ }^{101}$. L'écho intentionnel des assemblées clandestines vise à faire valoir l' « innocence » des aspirations protestantes et la « pureté » de leurs intentions ${ }^{102}$. Dès 1683, les dispositions réclamant que « ces assemblées ne se feront pas si secrètement qu'elles ne puissent être remarquées, afin que l'avis en puisse être donné à la Cour; que l'on connoisse que nous avons du zèle pour la gloire de Dieu $»{ }^{103}$ donnent le ton. Symptomatique du dessein de visibilité que valorisent les pasteurs, la nuance explicitée par Brousson résume éloquemment l'assignation prêtée, tout au long du siècle, à la résistance clandestine. Contrainte, elle vise à forcer une écoute, à encourager une reconnaissance. Loin d'une posture de dissimulation, tout un ensemble de démarches ouvertes jalonnent la résistance de l'ombre : lettres et conférences avec les députés du Régent, avec les commandants militaires et les ministres du roi, rapports officieux établis avec les intendants, s'inscrivent dans cet espoir et cette détermination tenaces à s'extraire de l'illicite, tantôt en faisant prévaloir le nombre et la résolution

100. Synode du Vivarais, 21 juin 1725 (art. XXI) : Les synodes du Désert, op. cit., t. I, p. 48.

101. BPF ms n $617 \mathrm{Q}$ : Lettre écrite à Mgr le duc de Richelieu par Messieurs les Pasteurs des Eglises des Cévennes, s.d., p. 479-480; Placet des protestants de Languedoc, pour se justifier sur l'accusation de manquer à la fidélité qu'ils doivent au roi, 1744, p. 528-535.

102. [A. Court], Apologie, op. cit., p. 30-32; Id., Abrégé d'histoire apologétique ou Défense des réformés de France, op. cit., p. 137; Synode national du BasLanguedoc, 18-21 août 1744 (art. X) : Les synodes du Désert, op. cit., t. I, p. 190.

103. Article 5 du Projet des Réformés fait au mois de May 1683, op. cit., p. 29-30. 
des insoumis, et les menaces d'une clandestinité forcée, tantôt en cherchant à trouver l'estime des ennemis ${ }^{104}$. À termes, l'objectif des réformés n'est pas de s'organiser en société secrète mais, par ce moyen, d'échapper à la répression sans jamais cesser de rappeler leur existence et d'insister sur la légitimité de leurs réclamations. En ce sens, il ne s'agit pas d'une foi $a u$ secret. Il aurait fallu pour cela vouloir se couper de tout. Or, l'extériorité est subie, et l'ambition demeure de réintégrer la société comme des sujets de plein droit.

Complexe sans être ambivalent, l'usage du secret en milieu protestant répond avant tout d'un temps d'oppression, autrement dit d'une contrainte. Circonscrit à certains domaines, quel rôle spécifique retenir? Celui d'éviter aux réformés de s'exposer aux coups de l'oppression et de nourrir leur fidélité en évitant la provocation. Jamais érigé en principe autre que sécuritaire, il reste un palliatif. S'il est le creuset d'un redressement spirituel et le point d'appui d'une reconquête ecclésiologique, le secret n'est pourtant qu'un volet de la résistance protestante, mis au service d'une persévérance. Aussi paradoxal que cela paraisse, il a une valeur de démonstration de force face à l'autorité : tout en visant à préserver les fidèles de la répression, il tend à faire connaître aux puissances les dispositions et la ferveur des clandestins. Moyen de survie, mode d'existence et d'opposition, outils de transgression - qui ne va pas sans risque d'introduire des pratiques hétérodoxes -, le secret sert une clandestinité tacite. L'opposition qu'il véhicule l'extrait de son caractère confidentiel. Les revendications qu'il soutient montrent qu'il n'est pas un retranchement mais une audace face à la censure. Voie d'affirmation d'une foi muselée, le secret a ici valeur de pamphlet. En tout cas, l'usage protestant qui en est fait montre qu'il put être bruyant et de notoriété publique.

chrystel.bernat@ephe.sorbonne.fr

104. A. Court, Mémoires, op. cit., p. 73, 105-106, 109, 116; Id., Apologie, op. cit., p. 42; Les synodes du Désert, op. cit., t. I, p. LXII. 